\title{
Cell-Based Therapy for Severe COVID-19 Patients: Clinical Trials and Cost-Utility
}

\author{
Ali Golchin ${ }^{1,2}$ (D) \\ Accepted: 24 September 2020 / Published online: 3 October 2020 \\ (C) Springer Science+Business Media, LLC, part of Springer Nature 2020
}

\begin{abstract}
The race among countries and companies to develop efficacious vaccines and therapeutics for the COVID-19 is ongoing fast, with many trials underway. Among this, cell-based therapy is focused on moderate to severe phases of COVID-19, and there have been promising outcomes. Mesenchymal stem cells (MSCs) due to their pro/anti-inflammatory and immune-modulatory behavior, Natural Killer (NK) cells thanks to their capacity of lysing virus-infected cells and regulate the resulting immune response, Dendritic cells thanks to immunotherapy and cell-based vaccine engineering, SARS-CoV2-specific T cells due to stimulate and promote the immune system and MSC-derived exosomes because of cell-free therapy and beneficial manufacturing aspects, hold great promises for cell-based therapy applications for treating COVID-19 and similar viral infections. Moreover, recently, an innovative approach to COVID-19 based on engineered human MSC has been introduced, which is continuously evacuated and degraded by the body's immune system during the antigen recognition process. However, the economic situation of governments and nations, and the cost of therapeutics influence the clinical approaches to manage and exit from this pandemic. This summary describes cell-based clinical trials and the cost-utility aspects of cell therapy. In this regard, limited clinical studies have been reported; while, several clinical trials have been approved for starting phases 2 and 3 of their trials for treating COVID19 patients with acute respiratory distress syndrome. Regarding the cost of cell therapy, many believe that the high cost of cellbased therapy will decrease substantially. Hence, there are hopes that cellular therapy can be approved soon for the treatment of viral diseases such as COVID-19.
\end{abstract}

Keywords COVID-19 $\cdot$ Cell-based therapy $\cdot$ Stem cell $\cdot$ Clinical trials $\cdot$ Cost

\section{Introduction}

The philosophy of cell-based therapy has revolutionized the field of regenerative medicine towards the natural physiological processes. Currently, several cell-based therapy approaches are undergoing clinical trials to reach an approved therapeutic of COVID-19. So far, stem cells, Natural killer (NK), Dendritic cells $(\mathrm{DN})$, and exosomes are the leading candidates of possible

This article belongs to the Topical Collection: Special Issue on COVID19 Pandemic and Stem Cells

Guest Editor: Mariusz Z. Ratajczak

Ali Golchin

agolchin.vet10@yahoo.com; Golchin_a@umsu.ac.ir

1 Department of Clinical Biochemistry and Applied Cell Sciences, Faculty of Medicine, Urmia University of Medical Sciences, Urmia, Iran

2 Regenerative Medicine Group (REMED), Universal Scientific Education and Research Network (USERN), Urmia, Iran therapeutics for COVID-19 treatment. Mesenchymal stem cells (MSCs) due to their pro/anti-inflammatory and immunemodulatory behavior [1], Natural Killer (NK) cells due to their capacity of lysing virus-infected cells and regulate the resulting immune response [2], Dendritic cells thanks to immunotherapy and vaccination, and MSC-derived exosomes thanks to cell-free therapy and beneficial manufacturing aspects, support the cellbased therapy application for treatment of COVID-19 and similar viral infections. Also, ALVR109 (AlloVir) as an allogeneic, virus-specific T-cell therapy has been introduced that this product is derived from healthy donors who have recovered from COVID-19. Recently, AlloVir declared the beginning of phase 1 clinical trials for this cell-based therapy. [Reference: https:// www.healio.com/news/hematology-oncology/20200918/fdaclears-ind-application-for-tcell-therapy-to-treat-highrisk-patientswith-covid19]. Moreover, an innovative approach to COVID-19 based on engineered human MSC has been introduced recently, which is continuously evacuated and degraded by the body's immune system during the antigen recognition process [3]. Chinese researchers have announced that the antibody response 
of this vaccine is effective and fast [3]. This approach has opened a new perspective for COVID-19 vaccine research.

Recently, multiple types of cell-based therapies (CBT) have been introduced. However, despite the massive surge in demand for CBT, especially stem cell therapies, these approaches remain quite expensive. For instance, a simple joint injection can cost approximately $\$ 1000$, and the cost of highlevel treatments can increase up to $\$ 100,000$ depending on the condition. In this regard, Lopes et al. used Bio-Solve software as an industry-standard modeling platform for modeling the costs of cell-based products. They used the production of autologous DCs for immunotherapy as a baseline model and concluded that the manufacturing costs of cell therapy treatments are anticipated to be more than $\$ 100,000$ per patient [4]. DC-based vaccination can create antigen-specific immune responses in patients with viral infectious diseases. Autologous peripheral blood mononuclear cells (PBMCs) can be cultured to produce a DC-based vaccine or frozen for future usage. The summary of this process is shown in Fig. 1. However, according to the Centers for Disease Control and Prevention (CDC) protocols, mild to moderate phases of COVID-19 are manageable by approved drugs and supportive therapies. Still, there are many concerns in the treatments of severe COVID-19 patients that using advanced technology therapeutics like cell-based therapy can be valuable here.

\section{Cell-Based Therapy and Cost Issue}

Generally, Cell-based therapies can be classified into two leading groups, including autologous and allogeneic. However, both of these groups can be used in clinical applications by minimal manipulations. The autologous source is produced at a small-scale, in a dedicated set, with localized manufacturing facilities close to the patients. One of the main challenges of autologous cell therapy is its inadequacy to take advantage of the target scale and cost-effectiveness in providing treatment for a complete treatment process. The preparation of autologous cell therapeutics is quite hand-operated and labor-intensive. The need for too many production workers, the lengthy culture times, and contaminations increase the risk of failure of the autologous cell-based therapies.

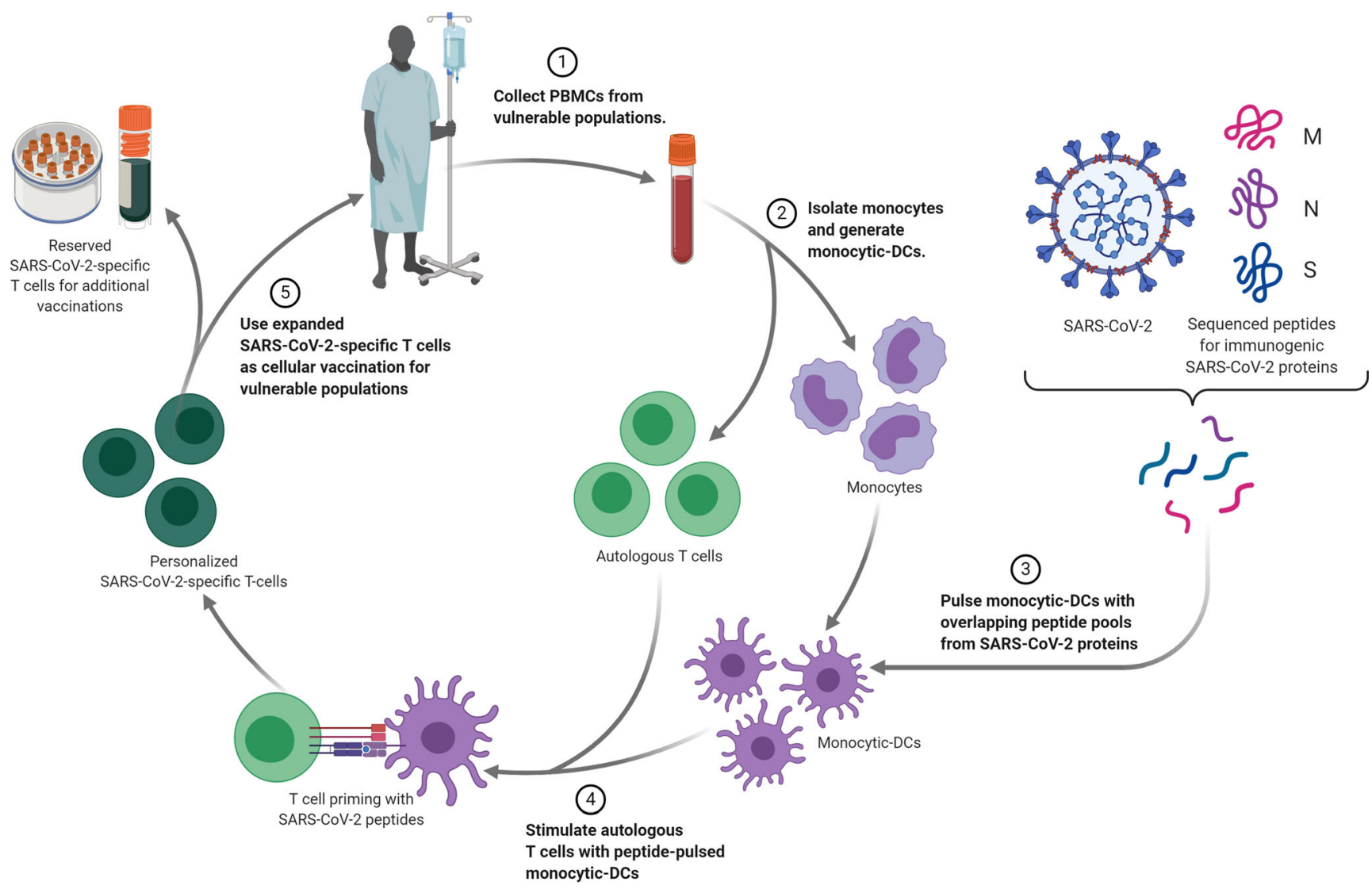

Fig. 1 Summary schematic of DC and monocyte-based therapy that can be used in COVID-19 treatment. This figure describes a strategy to generate a cell-based product as a potential therapeutic to prevent and treat COVID-19 patients. An individual's monocytic-DCs are pulsed with SARS-CoV-2 (The causative virus of the COVID-19) peptides and then used to prime that same individual's T cells to generate SARS-CoV-2- specific immune cells. These lymphocytic cells may be cryopreserved or infused into the vulnerable individual as prevention or treatment against COVID-19. ("Personalized Cell Therapies to Combat COVID-19", by BioRender.com (2020). Retrieved from https://app.biorender.com/ biorender-templates) 
On the other hand, production processes for allogeneic cell therapies are similar to other biologics. This source of cells can be increased and expanded using the existing scalable technologies and banked through cryopreservation for future applications. Therefore, allogeneic cell therapies are used to produce larger cell volumes at a reduced therapy cost. However, cell stability can be an obstacle with a long shelf time.

One of the main concerns in cell-based therapy is the cost issue. To date, there has been little published data on overall cell-based therapies costs. Unlike conventional therapeutics, cellular therapies should be delivered on-demand. Utilizing a proper dynamic cost model can help manufacturers to assess the implementation of maturing alternative technologies and determine the costs associated with the increased market for the product and future growth in demand [5]. A traditional biologics process has an average of 15 unit operations and based on cost per patient, labor and materials are assigned with the highest cost, among other parameters [4]. The media component for cell preparation must be provided according to Good manufacture practice (GMP) grade guideline, and after once use, the remaining content is discarded. Therefore, cell therapies are expensive to use in clinical applications. For instance, notwithstanding the significant progress in clinical research in the use of stem cell-based therapy in neurological diseases, the economic evaluation of these therapies is still at the initial stage [6]. However, there are several proposals that the cost of cell-based therapy can be decreased substantially when it becomes a mainstream treatment [5].

Generally, the standard framework for approving biological products covers cell, gene, and tissue-based products that are related to modifying or manipulating the cells of both autologous and allogeneic sources [7]. Commonly, biological products have higher prices in comparison to other drugs. For example, Zolgensma ${ }^{\circledR}$ (a gene therapy product for young children with spinal muscular atrophy) with a price US\$2.1 million is the most expensive drug ever. Other examples in this regard include CAR-T cell-based products such as Kymriah ${ }^{\circledR}$ (tisagenlecleucel) and Yescarta ${ }^{\circledR}$ (axicabtagene ciloleucel) [7] that cost US $\$ 475,000$ and US $\$ 373,000$, respectively for a one-time dose. Besides, stem cell therapy, as the most popular cell-based therapy, is not considered as a cost-effective option. A mere stem cell therapy can range from $\$ 4000-\$ 8000$ in the US and the cost for culturally expanded cells ranges from $\$ 15,000-\$ 30,000[8]$.

\section{Cell-Based Clinical Trials for COVID-19}

Among cell-based therapies, mesenchymal stem cell therapy has more registered clinical trials and has more chance to approve for COVID-19 treatment and even other similar viral infections. MSCs (Fig. 2a) and iPSC together are located in the first ranks of stem cell-based research and therapy. As we described in our previous study, in this regard, MSCs have several advantages such as intrinsic clinical properties, adequate clinical-based studies, distinct accessible sources, and the ability to store as cell banks that due to banking ability allogenic sources of MSCs are used in clinical application frequently (Fig. 2b). However, primarily clinical usage of these cells and other cell-based approaches need novel protocols and labor ability to manifest the best clinical outcomes. Therefore, we see that most of the cell-based clinical trials are executed in rich and developed countries (Fig. 2c).

As mentioned above, among cell-based therapies, MSCs have migration and homing ability, immunoregulatory function, anti-inflammatory effects, and multilineage differentiation potential. These characteristics have placed these cells at the top of the list of stem cell therapy options. In addition, the implied benefits of MSC therapy for treating COVID-19, notably in patients with ARDS, support the rapid start of clinical trials, adding the tender application of MSCs (Fig. 3) that have already documented safety profiles from FDA-approved clinical trials. As we know, MSC therapy does not have any unfavorable side effects on the patient. In 2010, a systematic review of several clinical trials involving over 1000 participants transplanted by intravascular MSCs for different diseases and clinical conditions including spinal cord injury, Crohn's disease, graft versus host disease, ischemic stroke, ischemic heart disease, and cardiomyopathy, with follow-up up from 2 weeks to 30 months partly assured the safety of MSC therapy [15]. In another recent systematic literature review and random-effects meta-analysis study, published clinical trials in all languages from 1990 to March 31, 2020, were reviewed. The results of this review showed that during the mentioned time, MSCs had been infused intravenously or intratracheally in 200 participants with follow-up term from 14 days to 5 years. Combined mortality rates showed a definite leaning; however, it did not attain statistical significance. During 2014-2020, several clinical studies published their results on MSC therapy for ARDS patients with safety results and/or without serious adverse events (Table 1) [10, 16-19]. Furthermore, several case reports have been published on MSC therapy in severe COVID-19 patients and demonstrated that MSC transplantation resulted in valuable clinical data on the treatment of COVID-19 and it may be an alternative approach for treating COVID-19, notably in patients with ARDS $[12,13]$. The MSCs could perform in two significant ways for the COVID-19 treatment, including in immunomodulatory effects and differentiation potency. Hence, we reviewed the reasons and outlook of using MSC in severe COVID-19 cases in a separate study and detail (see the reference [1]). During recent months, many clinical studies have been initiated, and several of them are in phases 2 and 3. Umbilical cord (especially umbilical cord blood and Wharton's jelly), bone marrow, menstrual blood, and the selected MSC therapy products of companies are the primary MSC sources that have been 


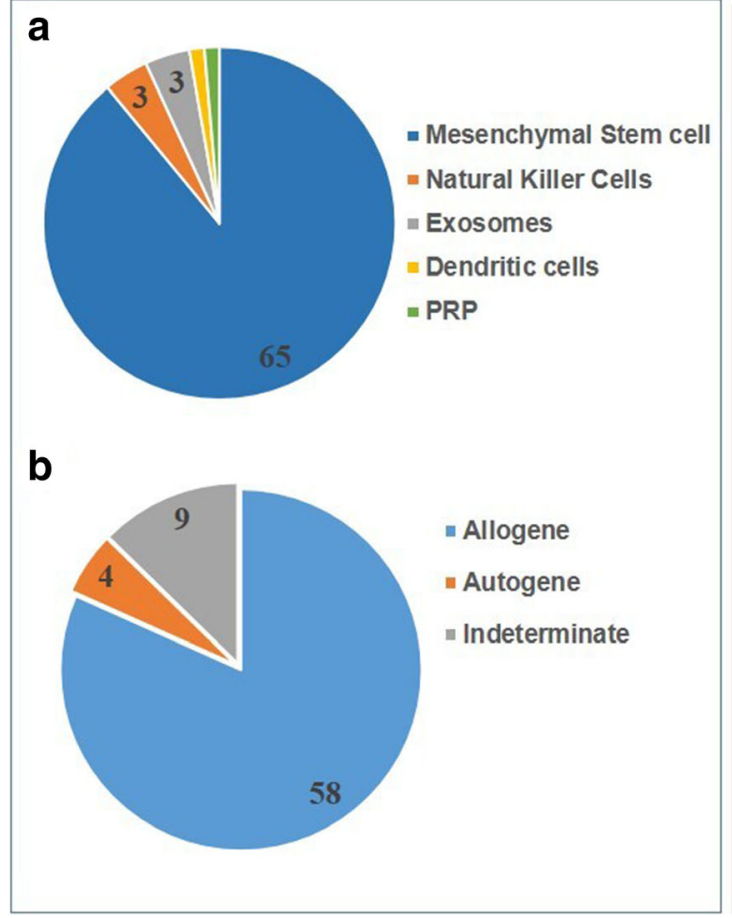

Fig. 2 Summary report of cell-based clinical trials for COVID-19 treatment that registered in https://clinicaltrials.gov/. a: The number of different cell types and cell-based products that are used in clinical trials;

utilized in these trials. NestCell ${ }^{\circledR}$ (Cellavita) and Remestemcel-L (Cellavita Mesoblast) are the leading companies in the introduction of MSC therapy for COVID-19 clinical trials. In a most recent study, exosomes derived from allogeneic bone marrow MSCs $\left(\mathrm{ExoFlo}^{\circledR}\right)$ were used as a treatment for 24 severe COVID-19 patients [14]. Given the safety profile, the ability to restore oxygenation, downregulated cytokine storm, and elevated immunity function, ExoFlo ${ }^{\circledR}$ can be considered as a promising therapeutic candidate for severe COVID-19 [14]. Therefore, a literature review has shown that MSC-based therapy significantly decreases the cytokine storm in severe COVID-19 patients.

Another candidate for cell-based therapy as an alternative treatment of COVID-19 patients is adoptive NK cells and CAR-NK cells. The NK cells are cytotoxic lymphocytes that contain $10-15 \%$ of total peripheral blood leukocytes in humans. These cells play a crucial role in bridging innate and adaptive immune system activity. During viral infection, the host cells become more responsive to NK cells and occur process through (i) upregulation of self-encoded molecules by infection/cellular stress; (ii) downregulation of ligands for inhibitory receptors which suppress NK cell activation, and (iii) direct identification of viral parts [20]. In a new report, Novocellbio (Incheon, South Korea) announced promising results using NOVO-NK, an autologous natural killer cell treatment, in a cellular and preclinical study. Hence, the company is leading additional preclinical studies to study the mechanisms used by NOVO-NK therapy against SARS-CoV-2 [21]. Recently, five clinical trials have been b: The original source of employed cells in registered clinical studies; $\mathbf{c}$ : As mentioned above, most of the cell-based clinical trials are executed in rich and developed countries

registered in Clinicaltrial.gov to evaluate the safety and immunogenicity of peripheral blood mononuclear cells (PBMCs)-derived NK cells from healthy donors in patients infected with COVID-19 by intravenous infusion. In one of these trials (Identifier: NCT04344548), patients will be treated with three different injections of NK cells $48 \mathrm{~h}$ apart with 1,10 , and 20,106 cells $/ \mathrm{kg}$ body weight. However, the protocols are unknown and clinical trials are in phases 1 and 2. However, The USA, China, and Colombia are the countries that are accelerating clinical trials in this regard; although, there have been no published clinical reports yet.

As mentioned above, Dendritic cells, due to immunotherapy and cell-based vaccination, are the next cell-based therapy candidate for COVID-19 treatment. In the USA, Aivita Biomedical company as an immuno-oncology company designing personalized vaccines, has recently started an adaptive Phase IB-II trial (Identifier: NCT04386252) of a vaccine consisting of autologous dendritic cells loaded with antigens from SARS-CoV-2, with or without GM-CSF, to prevent COVID-19 in adults $[22,23]$. These dendritic cells consist of peripheral blood monocyte-derived dendritic cells, which are obtained from the blood samples of patients. However, there is no more information about the results of this trial.

\section{COVID-19 and Cost Options}

A study has demonstrated that drugs to treat COVID-19 can be manufactured for minimum prices, between \$1 and \$29 
Table 1 the list of published MSC-based clinical studies for COVID-19 treatment

\begin{tabular}{|c|c|c|c|c|c|}
\hline MSC sources & $\begin{array}{l}\text { Number } \\
\text { of } \\
\text { patients }\end{array}$ & Result & Conclusion & Country & Ref \\
\hline hUC-MSCs & 12 & $\begin{array}{l}\downarrow \text { C-reactive protein } \\
\downarrow \text { IL-6 } \\
\uparrow \text { Lymphocyte } \\
\downarrow \text { Lung inflammation } \\
\quad \downarrow \text { Time to clinical } \\
\quad \text { improvement }\end{array}$ & $\begin{array}{l}\text { IV infusion of hUC-MSCs is a } \\
\text { safe and effective option for } \\
\text { severe COVID-19. }\end{array}$ & China & [9] \\
\hline ACE2- MSCs & 7 & $\begin{array}{l}\downarrow \text { C-reactive protein } \\
\downarrow \text { TNF- } \alpha \\
\uparrow I L-10 \\
\uparrow \text { Lymphocyte } \\
\downarrow \text { overactivated } \\
\quad \text { cytokine-secreting } \\
\quad \text { cells } \\
\text { pnulmonary function }\end{array}$ & $\begin{array}{l}\text { IV transplantation of MSCs } \\
\text { was safe and effective for } \\
\text { the treatment of COVID-19 } \\
\text { pneumonia patients, partic- } \\
\text { ularly for the patients in } \\
\text { critically severe conditions. }\end{array}$ & China & [10] \\
\hline AT-MSC & 13 & $\begin{array}{l}\downarrow \text { C-reactive protein } \\
\downarrow \text { IL-6 } \\
\downarrow \text { ferritin } \\
\downarrow \text { LDH } \\
\uparrow \text { Lymphocyte } \\
\uparrow \text { clinical improvement }\end{array}$ & $\begin{array}{l}\text { AT-MSC transplantation in } \\
\text { severe COVID-19 pneumo- } \\
\text { nia under mechanical venti- } \\
\text { lation in a small case series } \\
\text { did not cause significant ad- } \\
\text { verse events. It was follow- } \\
\text { ed by clinical and biological } \\
\text { improvement in most pa- } \\
\text { tients. }\end{array}$ & Spain & [11] \\
\hline hUC-MSCs & 1 & $\begin{array}{l}\downarrow \text { Inflammation } \\
\text { symptom } \\
\text { Throat swabs test } \\
\text { reported negative } \\
\text { after } 4 \text { days. }\end{array}$ & $\begin{array}{l}\text { Results demonstrated the } \\
\text { clinical outcome and great } \\
\text { tolerance of allogenic } \\
\text { hUC-MSCs therapy. }\end{array}$ & China & [12] \\
\hline $\begin{array}{l}\text { Allogeneic } \\
\text { MB-MSCs }\end{array}$ & 2 & $\begin{array}{l}\downarrow \text { Fraction of inspired } \\
\quad \text { O2 } \\
\downarrow \text { Bilateral lung exudate } \\
\quad \text { lesions }\end{array}$ & $\begin{array}{l}\text { MSC transplantation may } \\
\text { consider as an alternative } \\
\text { approach for treating } \\
\text { COVID-19, especially in } \\
\text { patients with ARDS. }\end{array}$ & China & [13] \\
\hline $\begin{array}{l}\text { Exosomes } \\
\text { Derived from } \\
\text { BM-MSCs } \\
\left(\text { ExoFlo }^{\mathrm{TM}}\right)\end{array}$ & 24 & $\begin{array}{l}\uparrow \text { Lymphocyte and } \\
\text { neutrophil count } \\
\downarrow \text { C-reactive protein } \\
\downarrow \text { IL-6 } \\
\downarrow \text { ferritin }\end{array}$ & $\begin{array}{l}\text { This product is a promising } \\
\text { therapeutic candidate for } \\
\text { severe COVID-19. }\end{array}$ & USA & [14] \\
\hline
\end{tabular}

hUC-MSCs (Human umbilical cord-MSCs), IV (intravenous), AT-MSCs (Adipose tissue-MSCs), MB-MSCs (Menstrual blood-MSCs), BM-MSCs (Bone Marrow-MSCs) per course [24]. They reported that minimum estimated costs of production could US $\$ 0.93 /$ day for Remdesivir, $\$ 1.45 /$ day for Favipiravir, \$0.08/day for Hydroxychloroquine, and $\$ 0.02 /$ day for Chloroquine, as main drugs for COVID-19 treatment [24]. Despite this, the current prices of these drugs are notably higher than the noted costs, especially in the US. Of course, different countries and companies act independently in this regard. For instance, while in North-America and European countries, the price of Remdesivir is $\$ 390$ per vial, its price is between $\$ 59$ to $\$ 71$ per vial in India and $55 \$$ per vial in Iran. Notably, a treatment course consists of using six vials of Remdesivir for five days. Besides, the exact price of the vaccine is not determined yet. However, Pfizer and its partner BioNTech (BNTX) has announced a deal to sell 100 million doses of the vaccine to the U.S. government for $\$ 1.95$ billion, so the price for the vaccine is $\$ 19.50$ per dose (if prescribed as a two-dose regimen, final cost will be $\$ 39$ per patient.). In addition, Cambridge, Mass-based Moderna, as one of the leading COVID-19 vaccine development companies, has estimated a price between $\$ 32$ and $\$ 37$ per dose of coronavirus vaccine. As mentioned above, cell therapies are expensive approaches; for instance, in a developed and 

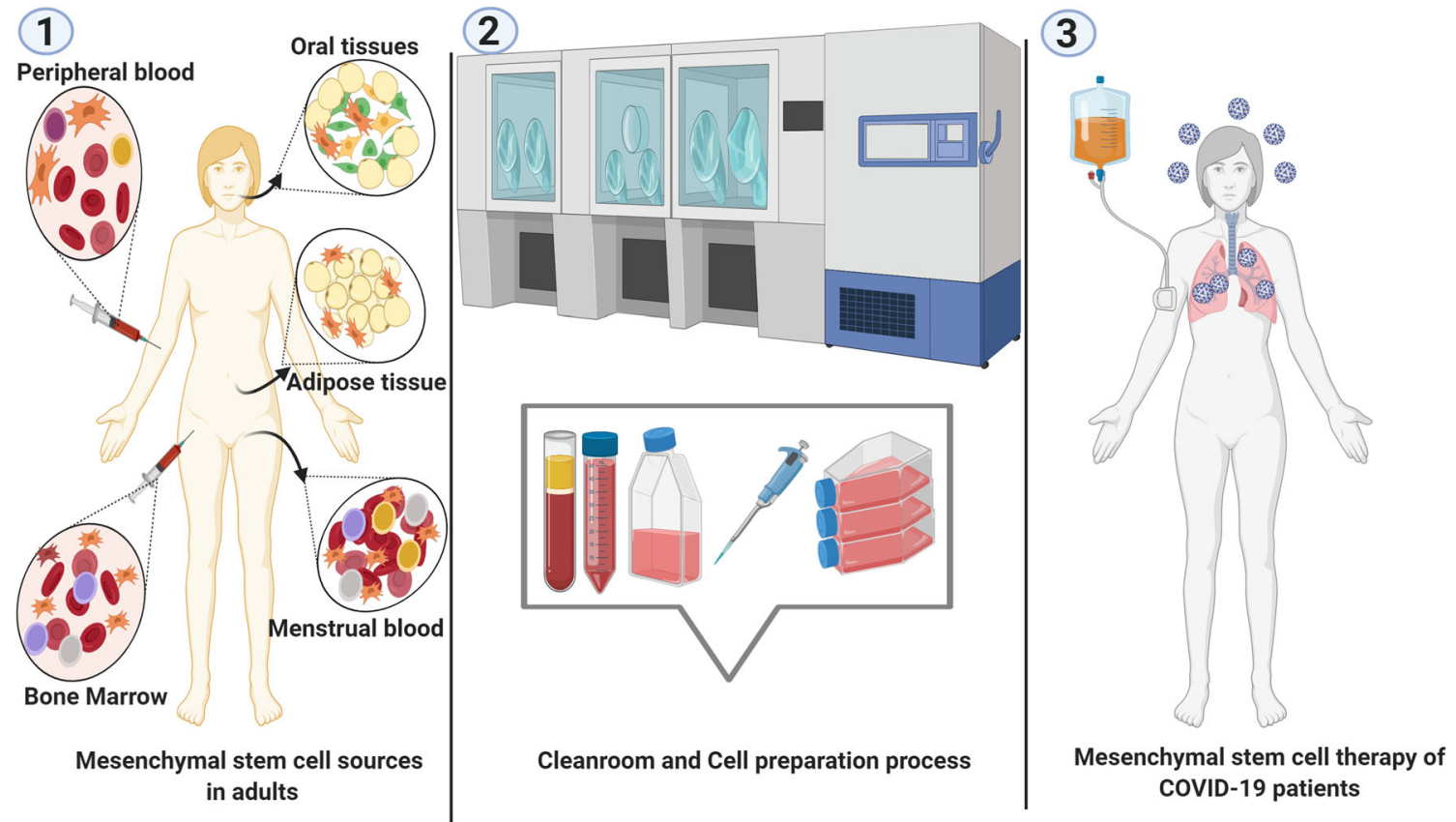

Fig. 3 Summary schematic of the MSC therapy process in COVID-19 patients, (1: Sources and extraction, 2: Minimal manipulation in the laboratory, 3: Intravenously infusion to patients). The figure is made with biorender (https://biorender.com/)

prosperous country like the US, stem cell therapy range from $\$ 4000$ - $\$ 8000$ on average without cell cultural expansion [25]. Indeed, it is countries and people, especially in lowand middle-income countries that have consider the economic aspects of medicine and choose the most efficient and economic treatment.

\section{Conclusion and Outlook}

The topics discussed in this paper can be summarized as a set of two propositions, including cell-based therapies for COVID-19 patients and the cost of these therapies. During recent months, more than 80 cell-based clinical trials have been started for COVID-19 treatments. This demonstrates that this field is one of the developing and promising trends of the present and future medicine. So far, MSCs and their derived exosomes, NK cells, and DN cells are the leading candidates of possible therapeutics for COVID-19 treatment. However, cost-efficiency is one of the principal parameters in clinical services, and currently, cell-based therapy is considered as an expensive medicine. However, there are a few proposals and protocols to lower the costs. Cell-tissue banking can play a notable role in decreasing the cost of cell-based therapies and it is a fundamental approach to promote cell therapy in clinical applications. Among different cell candidates, hematopoietic stem cells of cord blood (CB), MSCs of cord tissues (CT), and individual adipose tissues represent the most affordable sources for autologous and even allogenic banking sources. The history of CB banking is more than 20 years, with more than 30,000 stem cell-based cases, mostly in regenerative medicine.

Interestingly, both $\mathrm{CB}$ collection and $\mathrm{CB}$ banking costs per unit were lower in larger banks than in smaller banks. Therefore, more researches are needed to lower the cost of cell-based therapy and achieve a cost-effective approach. In conclusion, there is an essential need to advance safe and accessible COVID-19 treatments for low/middle-income countries. The race to develop effective vaccines and therapeutics for the COVID-19 is ongoing, with many trials underway. Among this, cell-based therapy has focused on moderate-severe phases of COVID-19, and there have been promising reports. Therefore, we necessarily need more research to have an adequate evaluation of the costeffectiveness of cell-based therapy and to guarantee sustainable access for patients and people.

Authors' Contributions A.G. conceptualized the study, drafting, writing the manuscript, and approving it for submission.

\section{Compliance with Ethical Standards}

Conflict of Interest The author has no conflicts of interest.

\section{References}

1. Golchin, A., Seyedjafari, E., \& Ardeshirylajimi, A. (2020). Mesenchymal stem cell therapy for COVID-19: Present or future. Stem Cell Reviews and Reports. Springer. doi:https://doi.org/10. 1007/s12015-020-09973-w. 
2. Cancio, M., Ciccocioppo, R., Rocco, P. R. M., Levine, B. L., Bronte, V., Bollard, C. M., ... Hanley, P. J. (2020). Emerging trends in COVID-19 treatment: Learning from inflammatory conditions associated with cellular therapies. Cytotherapy. Elsevier B.V. https://doi.org/10.1016/j.jcyt.2020.04.100.

3. Liu, J., Jiao, H., \& Yin, X. (2020). Engineered human mesenchymal stem cells as new vaccine platform for COVID-19. bioRxiv, 2020.06.20.163030. https://doi.org/10.1101/2020.06.20.163030

4. Adriana G. Lopes, A. S. B. F. (2018). Analysis of cost of cell therapy manufacturing: Autologous cell therapies, Part 1BioProcess International. BioProcess International, 16(3), 1-7. Retrieved from https://bioprocessintl.com/manufacturing/celltherapies/analysis-cost-of-cell-therapy-manufacturing-autologouscell-therapies-part- $1 /$.

5. Adriana G. Lopes, Andrew Sinclair, B. F. (2018). Cost analysis of cell therapy manufacture: Autologous cell therapies, part 2 BioProcess InternationalBioProcess international. Bioprocess International, 16(3), 1-7. Retrieved from https://bioprocessintl. com/manufacturing/cell-therapies/cost-analysis-of-cell-therapymanufacturing-autologous-cell-therapies-part-2/.

6. Nagpal, A., Milte, R., Kim, S. W., Hillier, S., Hamilton-Bruce, M. A., Ratcliffe, J., \& Koblar, S. A. (2019). Economic evaluation of stem cell therapies in neurological diseases: A Systematic Review. Value in Health. Elsevier Ltd. https://doi.org/10.1016/j.jval.2018. 07.878 .

7. Golchin, A., \& Farahany, T. Z. (2019). Biological products: Cellular therapy and FDA approved products. Stem Cell Reviews and Reports. Humana Press Inc. https://doi.org/10.1007/s12015018-9866-1.

8. Cona, L. A. (2020). The Cost of Stem Cell Therapy in 2020. Retrieved August 17, 2020, from https://www.dvcstem.com/post/ stem-cell-therapy-cost-2020

9. Shu, L., Niu, C., Li, R., Huang, T., Wang, Y., Huang, M., ... Feng, G. (2020). Treatment of severe COVID-19 with human umbilical cord mesenchymal stem cells. Stem Cell Research \& Therapy, 11(1), 361. https://doi.org/10.1186/s13287-020-01875-5.

10. Leng, Z., Zhu, R., Hou, W., Feng, Y., Yang, Y., Han, Q., ... Zhao, R. C. (2020). Transplantation of ACE2- mesenchymal stem cells improves the outcome of patients with COVID-19 pneumonia. Aging and Disease, 11(2), 216. https://doi.org/10.14336/AD. 2020.0228

11. Sánchez-Guijo, F., García-Arranz, M., López-Parra, M., Monedero, P., Mata-Martínez, C., Santos, A., ... Prósper, F. (2020). Adiposederived mesenchymal stromal cells for the treatment of patients with severe SARS-CoV-2 pneumonia requiring mechanical ventilation. A proof of concept study. EClinicalMedicine, $O(0)$. https:// doi.org/10.1016/j.eclinm.2020.100454.

12. Liang, B., Chen, J., Li, T., Wu, H., Yang, W., Li, Y., ... Hu, M. (2020). Clinical remission of a critically ill COVID-19 patient treated by human umbilical cord mesenchymal stem cells: A case report. Medicine, 99(31), e21429. https://doi.org/10.1097/MD. 0000000000021429.

13. Tang, L., Jiang, Y., Zhu, M., Chen, L., Zhou, X., Zhou, C., ... Li, L. (2020). Clinical study using mesenchymal stem cells for the treatment of patients with severe COVID-19. Frontiers of Medicine, 110. https://doi.org/10.1007/s11684-020-0810-9.

14. Sengupta, V., Sengupta, S., Lazo, A., Woods, P., Nolan, A., \& Bremer, N. (2020). Exosomes derived from bone marrow mesenchymal stem cells as treatment for severe COVID-19. Stem Cells and Development, 29(12), 747-754. https://doi.org/10.1089/scd. 2020.0080
15. Lalu, M. M., McIntyre, L., Pugliese, C., \& Stewart, D. J. (2010). Safety Of Cell Therapy With Mesenchymal Stromal Cells (MSCs): A Systematic Review. In American Thoracic Society International Conference Meetings Abstracts American Thoracic Society International Conference Meetings Abstracts (pp. A6043A6043). American Thoracic Society. https://doi.org/10.1164/ ajrccm-conference.2010.181.1_meetingabstracts.a6043.

16. Zheng, G., Huang, L., Tong, H., Shu, Q., Hu, Y., Ge, M., ... Xu, J. (2014). Treatment of acute respiratory distress syndrome with allogeneic adipose-derived mesenchymal stem cells: A randomized, placebo-controlled pilot study. Respiratory Research, 15(1), 39. https://doi.org/10.1186/1465-9921-15-39.

17. Wilson, J. G., Liu, K. D., Zhuo, H., Caballero, L., McMillan, M., Fang, X., ... Matthay, M. A. (2015). Mesenchymal stem (stromal) cells for treatment of ARDS: A phase 1 clinical trial. The Lancet Respiratory Medicine, 3(1), 24-32. https://doi.org/10.1016/S22132600(14)70291-7.

18. Freitag, J., Wickham, J., Shah, K., \& Tenen, A. (2020). Mesenchymal stem cell use in acute respiratory distress syndrome: A potential therapeutic application. Future Science OA, FSO584. https://doi.org/10.2144/fsoa-2020-0048.

19. Bellingan, G., Jacono, F., Bannard-Smith, J., Brealey, D., Meyer, N., Thickett, D., ... Ting, A. (2019). Primary Analysis of a Phase 1/ 2 Study to Assess MultiStem ${ }^{\circledR}$ Cell Therapy, a Regenerative Advanced Therapy Medicinal Product (ATMP), in Acute Respiratory Distress Syndrome (MUST-ARDS). In American Thoracic Society International Conference Meetings Abstracts American Thoracic Society International Conference Meetings Abstracts (pp. A7353-A7353). American Thoracic Society. https://doi.org/10.1164/ajrccm-conference.2019.199.1 meetingabstracts.a7353

20. Market, M., Angka, L., Martel, A. B., Bastin, D., Olanubi, O., Tennakoon, G., ... Auer, R. C. (2020). Flattening the COVID-19 curve with natural killer cell based immunotherapies. Frontiers in Immunology. Frontiers Media S.A. https://doi.org/10.3389/fimmu. 2020.01512

21. The Science Advisory Board staff writers (2020). Novocellbio's COVID-19 cell therapy shows promising results. Retrieved August 20, 2020, from https://www.scienceboard.net/index.aspx?

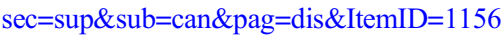

22. Phase Ib-II Trial of Dendritic Cell Vaccine to Prevent COVID-19 in Adults - Full Text View - ClinicalTrials.gov. (2020). Retrieved August 20, 2020, from https://clinicaltrials.gov/ct2/show/ NCT04386252?term $=$ Dendritic + cells \& cond $=$ Covid19\&draw $=$ 2 \&rank $=1$

23. SARS-CoV-2 Vaccine - AIVITA Biomedical (2020). Retrieved August 20, 2020, from https://aivitabiomedical.com/programs/ cancer-immunotherapy-2/.

24. Hill, A., Wang, J., Levi, J., Heath, K., \& Fortunak, J. (2020). Minimum costs to manufacture new treatments for COVID-19. Journal of Virus Eradication, 6(2), 61-69. https://doi.org/10. 1016/S2055-6640(20)30018-2.

25. Cona, L. A. (2020). The cost of stem cell therapy in 2020. DVCStem. Retrieved August 14, 2020, from https://www. dvcstem.com/post/stem-cell-therapy-cost-2020.

Publisher's Note Springer Nature remains neutral with regard to jurisdictional claims in published maps and institutional affiliations. 